\title{
Hernioscopy is a good option in strangulated inguinal hernias that retract under general anesthesia
}

\author{
Y. Özdemir · A. Z. Balta $\cdot$ K. Duman
}

Received: 14 July 2012/ Accepted: 24 August 2012/Published online: 7 September 2012

(C) Springer-Verlag 2012

\section{Dear Editor,}

We read with great interest the article entitled "Prognostic factors of postoperative morbidity and mortality in strangulated groin hernia" by Romain et al. [1]. The study aimed to find significant prognostic factors of postoperative morbidity and mortality, and the authors concluded that first intention exploratory midline laparotomy was a significant prognostic factor of postoperative mortality. In the minority of the patients with strangulated hernia, the contents of hernia sac can reduce spontaneously following the administration of muscle relaxants during induction of anesthesia, and an additional exploration will be necessary to inspect intra-abdominal contents. In their series, the authors had to perform an additional exploration in 12 patients, either with a midline laparotomy (3 patients with groin hernia, and 5 patients with femoral hernia) or with laparoscopy (1 groin hernia) or hernioscopy (3 groin hernia). While there were postoperative morbidity and

Y. Özdemir $(\bowtie) \cdot$ A. Z. Balta

Department of General Surgery,

Gulhane Military Medical Academy,

GATA Haydarpasa Training Hospital,

34668 Uskudar, Istanbul, Turkey

e-mail: dryozdemir@yahoo.com

K. Duman

Department of General Surgery,

Gumussuyu Military Hospital, Istanbul, Turkey mortality in 6 of 8 patients in laparotomy group, postoperative recovery after laparoscopy and hernioscopy was uneventful. Although choice of laparotomy might depends on a great suspicion of intestinal necrosis and effects the results, we think that hernioscopy rather than a laparoscopy is a good technique to start the evaluation of intraabdominal contents.

Hernioscopy is an alternative technique for laparoscopy, where the trocar was placed through the dissected hernia sac [2]. Hernioscopy allows a full exploration of peritoneal cavity without the need for laparotomy. In the presence of a suspicious view of an intestinal segment or necrosis, hernioscopy can also be used for retrieval of effected bowel by insertion of a second trocar [3]. In case of an inadequate evaluation, the technique can be switched to a laparoscopy. Thus, the possible complications of laparotomy, such as postoperative ileus, evisceration, increased length of hospitalization, and increased cost, can be prevented. Our clinical experience and the literature information support that hernioscopy is a safe and simple technique and very useful in the evaluation of retracted intestinal segments. To avoid from an unnecessary laparotomy, hernioscopy can be used as an initial diagnostic technique.

\section{References}

1. Romain B, Chemaly R, Meyer N, Brigand C, Steinmetz JP, Rohr S (2012) Prognostic factors of postoperative morbidity and mortality in strangulated groin hernia. Hernia 16:405-410

2. Binderow SR, Klapper AS, Bufalini B (1992) Hernioscopy: laparoscopy via an inguinal hernia sac. J Laparosndosc Surg 2:229-233

3. Kneessy K, Weinbaum F (1997) Hernioscopic retrieval of bowel for evaluation of viability during repair of a Richter's-type incarcerated femoral hernia. Surg Laparosc Endosc 7:171-172 